- RAM, REV. ADM. MACKENZIE, V. 12, N. 1 • SÃO PAULO, SP • JAN./FEV. 2011 - ISSN 1678-6971 •

Submissão: 24 jun. 2010. Aceitação: 12 nov. 2010. Sistema de avaliação: às cegas dupla (double blind review). UNIVERSIDADE PRESBITERIANA MACKENZIE. Walter Bataglia (Ed.), p. 204-227.

\title{
PUBLICAÇÕES PÓSTUMAS DE HENRI FAYOL: REVISITANDO SUA TEORIA ADMINISTRATIVA
}

EDSON MIRANDA DE SOUZA

Mestre em Administração pela Faculdade de Ciências Empresariais da Universidade Fundação Mineira de Educação e Cultura (FUMEC).

Financial Controller do Departamento Financeiro da Bucyrus International. Avenida Afonso Pena, 4.100, $6^{\circ}$ andar, Belo Horizonte - MG - Brasil - CEP 30130-009

E-mail: emdesouza@hotmail.com

\section{AFRÂNIO CARVALHO AGUIAR}

Doutor em Administração pela Faculdade de Ciências Econômicas da Universidade Federal de Minas Gerais (UFMG).

Professor da Faculdade de Ciências Empresariais

da Universidade Fundação Mineira de Educação e Cultura (FUMEC). Rua Sagitário, 427, Sala 6, Belo Horizonte - MG - Brasil - CEP 30360-230 E-mail:aguiar.afr@terra.com.br 


\section{RESUMO}

O engenheiro francês Henri Fayol (I84I-I925) é usualmente apresentado aos estudantes de Administração como o Pai da Escola Clássica de Administração, o que demonstra uma representação limitada da amplitude de sua contribuição para a evolução do pensamento administrativo. Além disso, é frequentemente associado ao seu contemporâneo, o teórico norte-americano Frederick Taylor, sendo aos dois atribuída a defesa de um modelo autoritário de administração. Entretanto, recentemente, pesquisadores descobriram, através do exame de documentos raros e inéditos, um desconhecido retrato desse pioneiro. Este trabalho resulta de uma investigação que buscou levantar fontes de informação bibliográfica disponíveis, publicadas ou não, incluindo resultados de trabalhos de pesquisadores da França, dos Estados Unidos, do Canadá, da Austrália e do Japão. Esses pesquisadores compõem um reduzido grupo de estudiosos, aqui denominados "novos fayolistas" porque retomam, depois de anos de quase amnésia no meio acadêmico, o interesse pelas contribuições de Henri Fayol. Tais estudos revelam conceitos desenvolvidos por Fayol que antecipam aspectos de teorias e práticas da Administração que, somente mais tarde, seriam desenvolvidas, como a Escola de Relações Humanas, a Teoria Contingencial e o Planejamento Estratégico. Ao apresentar as recentes pesquisas sobre o homem e o teórico Henri Fayol, este estudo permite, aos docentes e estudantes de língua portuguesa, acesso a escritos e palestras de sua autoria que, até então, permaneciam desconhecidos.

\section{PALAVRAS-CHAVE}

Henri Fayol; Administração; Estratégias organizacionais; Teoria organizacional; Planejamento. 


\section{INTRODUÇÃO}

Depois de mais de noventa anos da publicação de sua obra-prima, Administration Industrielle et Générale (AIG), Jules Henri Fayol (I84I-I925) ainda desperta controvérsias. Uma análise mais ampla de seus trabalhos revelará ao leitor do século XXI um autor surpreendentemente contemporâneo. Com efeito, questões que só vieram a entrar nas agendas de estudos organizacionais da Escola de Relações Humanas, na década de I930, ou da Teoria das Contingências, efervescentes a partir de I970, foram de alguma forma discutidas por Fayol décadas antes. Henri Fayol geralmente é lembrado apenas como o Pai da Escola Clássica de Administração e isso não representa com a clareza necessária sua efetiva contribuição para a Ciência da Administração nem lhe faz justiça. Ao contrário, do estudo mais profundo da sua obra emerge um pensador muito mais complexo e multidimensional do que o estereótipo convencional que o identifica com a Escola Clássica.

De certa maneira, Fayol parece ter sido vítima da cronologia e da história. Tendo apresentado suas ideias na mesma época que o norte-americano Frederick $\mathrm{W}$. Taylor, os ambientes econômicos e políticos da primeira metade do século XX contribuíram para que o norte-americano o ofuscasse. Ao mesmo tempo que a história da Administração os colocava no mesmo patamar, citando suas contribuições, frequentemente, como equipotentes no plano cronológico e valorativo, o que também pode ser considerado uma subestimação de seu verdadeiro papel histórico, bem como do alcance de suas contribuições para o desenvolvimento da teoria gerencial. Ademais, a relevante influência do enfoque anglo-saxão na construção do pensamento administrativo pode ser uma das razões para o relativo obscurantismo existente em relação às reais contribuições do francês Henri Fayol (nascido em Constantinopla, atual Istambul, Turquia, em uma família de origem francesa). Tendo bebido da fonte do positivismo, notadamente dos pensamentos do compatriota e contemporâneo Émile Durkheim (I858-I9I7), Fayol viria a desenvolver teorias e práticas que ainda não são plenamente conhecidas e estudadas.

Uma releitura de Fayol pode apresentá-lo, pois, como um executivo dotado de flexibilidade, com foco na estratégia, trabalhando dentro de um contexto situacional, antecipando tendências que somente muito depois seriam disseminadas por outros doutrinadores. De acordo com Parker e Ritson (2005a, p. I89), Fayol possuía uma orientação para a ciência social em contraponto a Taylor: "Suas teorias de Administração abraçam aquilo que hoje poderia ser reconhecido como uma perspectiva social e científica interdisciplinar, em comparação com a orien- 


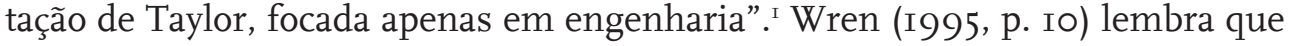
Fayol indicou a necessidade do planejamento de longo prazo e de adaptação às mudanças ambientais: "Ao contrário do mito perpetuado por escritores modernos, Fayol não via a empresa como um sistema fechado".

Contrariando esse perfil estereotipado do teórico Henri Fayol, ainda predominante no mundo acadêmico do século XXI, pesquisadores contemporâneos que examinaram Fayol em profundidade encontraram um teórico, executivo, administrador e educador de visão ampla e à frente de seu tempo.

\section{DESVENDANDO FAYOL: OS VELHOS E OS NOVOS FAYOLISTAS}

A revisão dos registros científicos sobre Henri Fayol revela apenas um pequeno número de estudos que abordam sua história de vida ou sua contribuição à Administração moderna. Todavia, alguns poucos autores se ocuparam desse importante teórico e desenvolveram pesquisas que permitiram divulgar alguns de seus trabalhos praticamente inéditos, realçando a contemporaneidade de suas ideias. Dentre eles, encontram-se Breeze (1980; I98I; I985; I995), Reid (I986; I988; I995), Wren (I995; 200I) e Wren, Bedeian e Breeze (2002). Mais recentemente, foram publicados os estudos de Peaucelle (2003a) e Parker e Ritson (2005a; 2005b). Um estudo que exigiu pesquisa mais elaborada sobre o homem Fayol foi desenvolvida por Sasaki (1987; 1995). De certa forma, esgotam-se com essas poucas referências as obras disponíveis internacionalmente sobre Fayol.

Esse fato ajuda a explicar por que a sua real dimensão como teórico e administrador estratégico seja relativamente obscura para os estudiosos e executivos da atualidade, uma vez que seus estudos, propagados em especial por Wren, Bedeian e Breeze (2002) e por Peaucelle (2003a), ainda não ecoaram a ponto de iluminar o desconhecimento que cerca a obra de Fayol em sua totalidade.

Sabe-se, entretanto, que os textos de Fayol, até então inéditos: I. a terceira parte de Administration Industrielle et Générale $3^{\text {ème }}$ partie (AIG): observations et expériences personnelles (FAYOL, 2003a), publicada por Jean-Louis Peaucelle em 2003 em sua obra Henri Fayol: inventeur des outils de gestion; 2. o discurso intitulado L'exposé des principles généraux d'Administration, um resumo magistral do pensamento de Fayol tornado público por Wren, Bedeian e Breeze (2002) e 3. as profícuas anotações de Fayol, arquivadas no Centre d'Histoire de l'Europe du $20 e$ siècle (Fondation des Sciences Politiques) em Paris, e também estudadas e publica- 
das por Peaucelle (2003a), que se constituem em novas descobertas que vieram a ampliar em muito o leque de conhecimento sobre Fayol.

Neste ponto, vale introduzir uma nova classificação das gerações de fayolistas, para compreender as diversas fases que separam e determinam os estudos sobre sua obra. A primeira geração é composta por seus seguidores diretos, seus discípulos, principalmente aqueles que trabalharam com ele na divulgação da doutrina. Fazem parte desse grupo, dentre outros, Paul Vanuxem, Joseph Wilbois e Robert Desaubliaux - casado com uma neta de Fayol (Joseph Carlioz) -, diretor da empresa Comambault, trabalhou com Fayol durante muitos anos (BREEZE, I985), Georges Lachapelle, Maxime Leroy, Sainte-Claire Deville, Paul Devinat, Charles de Freminville, Mazerat e Henri Verney, que publicou em I925 a primeira biografia do mestre. Esses autores, os primeiros fayolistas, publicaram seus trabalhos nas primeiras duas décadas do século XX. A segunda geração de fayolistas, da qual Gulick e Urwick são expoentes, continuou a divulgação das ideias de Fayol nas décadas subsequentes, até o início dos anos I950. A partir dessa época e até o final da década de i970, verifica-se uma relativa lacuna com respeito à divulgação do fayolismo. São quase 30 anos, nos quais o nome de Henri Fayol praticamente não passou do que Bedeian (I998) viria a chamar de um capítulo obrigatório na história. Durante esse período, vamos encontrar apenas os esparsos textos de Blancpain (1974) e de Brodie (I967), fazendo que o tema Fayol e suas ideias permanecessem em sono profundo, em uma época que vivenciou grandes transformações na sociedade e, consequentemente, nos negócios.

A partir de I980, entretanto, uma terceira onda de pesquisadores traz o tema à tona, em uma sucessiva leva de textos que se estendem aos dias de hoje, ainda que circunscritos a um pequeno número de estudiosos. Tal processo teve início com a apresentação da dissertação de mestrado de John D. Breeze para o Master of Business Administration Program da Saint Mary's University, em Halifax, Canadá: Henri Fayol's - Résumé de la doctrine administrative: translation, commentary and analisys of its historical development. Breeze (I980, p. 2) justifica a importância de seu trabalho, afirmando que apesar de Fayol ter continuado a escrever após a publicação de AIG, esses textos permaneciam inéditos: "Considerando o valor de sua contribuição e seu mérito, é uma surpresa que uma avaliação definitiva de sua vida e de seu trabalho esteja ainda por ser publicada, seja em inglês ou em francês". O autor ressalta, ainda, a dificuldade de acesso ao trabalho de Fayol fora da França, mostrando que apenas alguns poucos eruditos, entre eles Bedeian (I979), Brodie (I967), Cuthbert (I970), Dale (I960) e Urwick (I937) (a segunda geração de fayolistas) tinham publicado informações adicionais que permitiram um melhor entendimento de sua vida e de sua contribuição à Administração. 
Depois de quebrar essa amnésia histórico-científica, o canadense John D. Breeze (I98I; I985; I995) passou a publicar uma série de estudos sobre o tema Fayol, tornando-se o precursor dos "novos fayolistas", ao qual vieram se juntar o francês Jean-Louis Peaucelle e o norte-americano Daniel A. Wren, da Oklahoma University; o americano Donald Reid da North Caroline University; o australiano Lee D. Parker da University of Adelaide, e o japonês Tsuneo Sasaki. Também integra esse grupo o veterano (fayolista da segunda geração) Arthur G. Bedeian, professor da Louisiana State University.

Os novos fayolistas em muito ampliaram, durante as duas últimas décadas, o conhecimento público sobre a vida e a obra de Henri Fayol, trazendo aos estudantes de Administração textos inéditos do próprio teórico, além de artigos em que analisam e dissecam sua vida, sua visão estratégica e a contemporaneidade de seu pensamento.

Em sua dissertação de mestrado, Breeze (I980) procurou preparar uma bibliografia que cobrisse a produção de Fayol nos campos da Administração e do Gerenciamento. Naquela época, ele apontou as dificuldades dessa tarefa. A partir de trabalhos anteriores sobre o tema, Breeze (I980, p. 34) classifica a bibliografia preparada por Bedeian, em I979, como a mais completa existente até então, ressalvando, contudo, que "como Bedeian observou, as primeiras bibliografias eram incompletas e nem sempre concordavam nos títulos e nas datas".

Peaucelle (2003c) também apresenta uma bibliografia de Fayol que cobre suas publicações iniciais sobre Geologia e sobre Administração. Aqui também se pode verificar inconsistência nas datas e nos títulos dos estudos, quando se comparam essas duas com outras fontes de informação.

No que tange os trabalhos relacionados com a Administração, a bibliografia apresentada pelos autores mostra pequenas divergências. Isso pode ser justificado pelo fato de que os trabalhos de Fayol não foram publicados de forma sistemática. Seus textos derivam, principalmente, de palestras e conferências cujas anotações foram apenas parcialmente publicadas, notadamente em periódicos científicos. Enquanto um autor menciona a data da referida palestra, outro menciona a data do periódico que a publicou. Também existem textos que foram publicados por mais de um periódico, em datas diferentes.

Prosseguindo, Breeze (I980) informa que Fayol ministrou conferências na École Supérieure de Guerre, em I920. Para Peaucelle (2003d), no entanto, duas conferências teriam sido proferidas naquela instituição, mas em 5 e I4 de maio de I923. Esse caráter disperso da produção de Fayol, a falta de uma publicação sistemática de seus textos e o desaparecimento dos arquivos do Centro de Estudos Administrativos - CEA (BRODIE, I967 apud BREEZE, I995) são fatores que contribuem para dificultar uma investigação mais aprofundada de sua contribuição científica à ciência da Administração. Assim, com referência ao discurso 
pronunciado em I908, Breeze (I980) o denomina L'exposé des principles généraux d'administration, destacando que se trata de texto mantido inédito pela família do autor. Peaucelle (2003d, p. 292), por seu lado, o referencia como: "Resumé dans les publications de la Société de l'Industrie Minérale”, cujo congresso, acontecido na região de Saint-Étienne, foi realizado em i6 de junho de I908.

Naquela data, Fayol apresentou seus Princípios Gerais de Administração para uma audiência formada por colegas da indústria mineral francesa. O texto dessa palestra, que antecede a publicação de AIG, foi disponibilizado pelo filho de Fayol, Henri Joseph Fayol, a Bedeian, em I975, e somente tornado público por Wren, Bedeian e Breeze em 2002. A tradução para o inglês foi feita por Daniel A. Wren, que faz referência ao texto em Wren (I995, 200I). Ou seja, nesse período, o texto inédito circulou apenas entre os membros do restrito grupo dos novos fayolistas. Fato é que esse texto original, datilografado em francês, somente foi publicado em 2003, por Jean-Louis Peaucelle, que o obteve de Bedeian, então detentor do referido documento. Nessa palestra, ministrada na mesma escola onde tinha estudado, a St. Etienne School of Mines, Fayol faz um retrospecto da história da empresa Comambault em evento que celebrava o cinquentenário da empresa dirigida por ele havia 20 anos.

Esse texto de Fayol apresenta uma análise dos fundamentos de sua teoria administrativa, contrariando a crença corrente de que, no momento histórico em que viveu e trabalhou, a teoria administrativa encontrava-se ainda em seus primórdios. Vários teóricos da Administração defendem que, pelo menos até a década de I930, os administradores enfrentavam um ambiente empresarial essencialmente mecanicista, longe de conhecer ou praticar os princípios organicistas que as empresas vieram a adotar somente muitos anos depois. Além disso, no que tange ao planejamento dos negócios, nessa época ainda vigoravam procedimentos e práticas características dos estágios iniciais da evolução dessas atividades, exercidas por administradores que não possuíam visão estratégica apurada, atuavam predominantemente de forma apenas reativa e nem mesmo chegavam ao estágio em que o planejamento se fazia por extrapolação do passado. Essas questões, ligadas aos conceitos e práticas administrativas vigentes, passam a ser mais bem discutidas a seguir.

\section{A TEORIA E AS PRÁtICAS ADMINISTRATIVAS DE FAYOL}

Fayol inicia o mencionado discurso, pronunciado em I908, explicando que o desenvolvimento das indústrias metalúrgicas no norte e no leste da França prejudicou a existência de fábricas no centro do país, onde se localizava a empresa, 
formada por diversas unidades de mineração de carvão e metalurgia. Com o fechamento de minas, que apresentavam alto custo de exploração, e com a redução dos resultados, em I885 a empresa suspendeu o pagamento de dividendos e encontrava-se à beira da falência. Em I888, houve uma mudança na administração com Fayol assumindo sua presidência, no momento em que a empresa estava quase resignada a fechar e abandonar suas fábricas e a suspender suas operações nas minas. A partir de então, a empresa tornou-se novamente lucrativa e sua recuperação foi contínua e substancial. Fayol (2002, p. 9I0; 2003b, p. I80) enfatiza que:

A história da empresa mostrará que seu declínio e recuperação se deveram somente aos procedimentos administrativos utilizados. Isto aconteceu com as mesmas minas, as mesmas fábricas, os mesmos empregados.

Falando aos jovens engenheiros, Fayol enfatizou que o sucesso de uma empresa depende muito mais da habilidade administrativa de seus líderes do que de suas habilidades técnicas:

É certo que o líder que é um bom administrador mas tecnicamente medíocre é, em geral, mais útil para uma organização do que se ele for um brilhante técnico, mas um administrador medíocre (FAYOL, 2002, p. 9II; 2003b, p. I80).

Na sequência, Fayol discorre sobre Administração, definindo-a como

[...] governar ou gerenciar negócio público ou privado. Isto significa procurar fazer o melhor uso possível dos recursos disponíveis para atingir os objetivos da organização. Administração inclui, portanto, todas as operações da organização (FAYOL, 2002, p. 9II; 2003b, p. I80).

Wren, Bedeian e Breeze (2002, p. 916) lembram que "caso os tradutores posteriores [de AIG] tivessem tido conhecimento desta definição explicitada em

2 Os autores se referem à celeuma causada pelas traduções da AIG para o inglês, em I949, por Constance Storrs, que o intitulou General and Industrial Management, diferentemente da tradução de Coubrough em I930, que havia sido Industrial and General Administration. Os anglo-saxões entendiam administration como o gerenciamento de entidades governamentais, enquanto management referir-se-ia a organizações comerciais e industriais. Esses detalhes teriam contribuído para prejudicar a compreensão da universalidade do pensamento de Fayol no mundo anglo-saxão (REID, I995). Peaucelle (2003a) lembra que falta essa definição na AIG, ocasionando a polêmica sobre a maneira de se traduzir a palavra [francesa] Administration. 
I908, então nós não teríamos testemunhado a batalha semântica sobre o que era administration e o que era management".

Com esta clara definição, Fayol mostra que seu enfoque era direcionado para a administração em geral, e não para funções específicas de uma organização, sendo orientado para guiar a organização na busca por seus objetivos. Define, assim, as responsabilidades de um departamento administrativo:

Alguém poderia definir o departamento administrativo dizendo que ele inclui tudo que não é parte de outros departamentos [técnico, comercial e financeiro], mas podemos definir isto de uma maneira mais positiva, dizendo que ele é especificamente responsável por: I - garantir que unidade de ação, disciplina, antecipação, atividade, ordem, etc. existam em todas as partes da organização; 2 - recrutamento, organização e direção da força de trabalho; 3 - garantir o bom relacionamento entre os vários departamentos entre si e com o mundo exterior; 4 - fazer convergir todos os esforços em direção ao objetivo social; 5 - dar satisfação aos acionistas e aos trabalhadores, ao trabalho e ao capital (FAYOL, 2002, p. 9II; 2003b, p. I80).

A tradução livre acima foi realizada valendo-se do original em francês (PEAUCELLE, 2003a) e dos textos em inglês (WREN; BEDEIAN; BREEZE, 2002) e, somente por esse pequeno trecho, fica evidente o risco de perda de essência decorrente da tradução de um idioma para outro e desse para um terceiro. O texto em inglês traduz service administratif (que poderia ser entendido como uma atividade, algo mais genérico) como administrative department (que remete, claramente, a uma área da organização, algo mais específico, portanto, com evidente perda de substância do significado original). Também, e somente a título de exemplo, ao final do quinto objetivo do texto em inglês, tem-se a expressão labor and management, que poderia ser vertida para o português como "os trabalhadores e a gerência", enquanto o texto original fala em au travail e au capital (ao trabalho e ao capital), opção escolhida pelos autores deste trabalho.

O texto mostra a preocupação de Fayol em antecipar-se, ao contrário do pensamento corrente de que os teóricos de sua época possuiriam apenas uma atitude reativa e a posteriori (ANSOFF; McDONNELL, 2009). Ao mesmo tempo, Fayol prega, como relata Wren (I995), a necessidade de relacionamento com o mundo exterior, um enfoque diferente da visão de Morgan (2007), que enxerga os "clássicos" tratando a organização como um sistema mecânico, fechado e voltado para dentro.

A convergência de esforços para atingir os objetivos da organização e a interação entre as suas diversas atividades exemplificam a orientação orgânica que 
Fayol julgava deveria prevalecer no contexto corporativo. Isso ele demonstra, por meio de metáfora biológica, ao definir como deveria funcionar o "Departamento Administrativo":

Não existe uma linha clara de demarcação entre o departamento administrativo e os outros departamentos; eles se entrelaçam, se interpenetram, se influenciam mutuamente, ele interage com os outros apesar de manter-se distinto, como, por exemplo, o sistema nervoso e as outras funções do corpo humano. $\mathrm{O}$ departamento administrativo, assim como o departamento técnico, possui subsidiárias em todas as áreas e até mesmo nas mais detalhadas ramificações da organização social (FAYOL, 2002, p. 9II; 2003b, p. I8I).

Essa ideia de interpenetração desses "serviços administrativos" com outros "serviços" é considerada confusa por Peaucelle (2003b), que questiona se Fayol estaria se referindo a estruturas ou funções. A interpretação como "função" parece ser mais lógica, admitindo que o conceito de "administrar" se espraia por toda a organização. Mais ainda, fortalecendo essa hipótese, o texto original fala em l'organisme social, algo mais próximo do sentido sociológico do que da concretude da organização empresarial, e que, em outras partes do texto, Fayol denomina enterprise.

O uso de metáfora biológica também deve ser destacado, por seu pioneirismo. De fato, para a maioria dos estudiosos, somente a partir da década de I930 os teóricos da Administração passaram a utilizar a Biologia como inspiração (MORGAN, 2007). No entanto, conforme observam Parker e Ritson (2005a, p. I85), "Fayol frequentemente empregava metáforas biológicas para expressar suas idéias".

Ainda no discurso de I908, Fayol discorre sobre a dificuldade em se obter competência administrativa, opondo-a ao conhecimento técnico. Para o teórico, na falta de ensino e de princípios estabelecidos, cada um possui apenas sua própria experiência e as lições aprendidas com a prática. Por isso, enfatiza, é necessário criar regras para fazer frente a problemas complexos, em meio a sistemas que são frequentemente contraditórios, evitando que cada um utilize suas próprias regras.

Fayol discute, portanto, a necessidade de se construir uma teoria, deixando claro que o sucesso ou o fracasso de uma organização depende dos homens que a dirigem. Esses devem possuir conhecimentos de Administração e não somente competência técnica: 
Antecipar, decidir e agir. Conheça os homens e saiba utilizá-los. Alguém pode ser um grande estudioso, conhecer a fundo mineração e metalurgia e não conhecer nada sobre estas coisas. Em uma organização industrial, os homens que atingem o topo são caracterizados muito mais por suas qualidades administrativas do que por seus conhecimentos científicos ou técnicos. [...] E, sem diminuir a importância da habilidade técnica, a qual é sempre necessária nos negócios, às vezes até indispensável, podemos dizer que, em geral, o valor de um homem depende, sobretudo, de sua habilidade administrativa. Isto é verdade não somente para o diretor, mas para todos os empregados que participam da administração de uma organização, do mais poderoso ao mais modesto (FAYOL, 2002 p. 9II-9I2; 2003b, p. I8I).

Fayol seria, com a AIG, um defensor da possibilidade e da necessidade do ensino de Administração, outro pioneirismo do mestre, e não somente para os profissionais envolvidos na gerência de negócios, já que, no seu entendimento "a capacidade administrativa pode e deve adquirir-se, assim como a capacidade técnica, primeiramente na escola e depois na oficina” (FAYOL, I994, p. 38). Assim, para o teórico:

Todos têm necessidade, em maior ou menor grau, de noções administrativas. Na família, nos negócios do Estado, a necessidade de capacidade administrativa está em relação com a importância da empresa; para os indivíduos, essa necessidade é tanto maior quanto mais elevada é a posição que ocupam (FAYOL, I994, p. 39).

Parker e Ritson (2005a) lembram que a educação é um dos fundamentos da carreira de Fayol, tornando-se uma renovada preocupação ao final de sua vida profissional. Ele promoveu a noção de que Administração é uma disciplina acadêmica e profissional, devendo ser ensinada em todos os níveis, fluindo das escolas para os negócios.

Fayol (2002, 2003b) apresenta, então, o que denomina Princípios de Administração, um elenco de dez itens. Esses itens formam a base dos I4 princípios que mais tarde desenvolveria em AIG, os quais são sempre analisados, ainda que muitas vezes superficialmente, pelos autores que discorrem sobre Fayol. Neste trabalho enfatizam-se apenas os aspectos relativos aos princípios relacionados que resultam, em especial, das contribuições trazidas pelos "novos fayolistas" à melhor compreensão do mestre francês. 


\subsection{UNIDADE DE COMANDO}

O princípio da unidade de comando é apresentado por Fayol como fundamental, dele derivando outros princípios secundários. De acordo com Peaucelle (2003b), essa noção de princípio fundamental e de corolários é uma tentativa de axiomatização das ciências de gestão, vindo a influenciar os trabalhos do britânico Lyndall Urwick muitos anos depois.

\subsection{TRANSMISSÃO HIERÁRQUICA DE ORDENS - A CADEIA DE COMANDO}

No discurso de 1908, Fayol trata da necessidade da hierarquia para a transmissão de ordens, de forma conceitual, trazendo o princípio da cadeia de comando que, de certa forma, pode ser extrapolada na constituição de estruturas organizacionais para diferentes tipos de negócios, estruturas e tamanhos (FAYOL, 2002, 2003b).

\subsection{SEPARAÇÃO DE PODERES - AUTORIDADE, SUBORDINAÇÃO, RESPONSABILIDADE E CONTROLE}

Fayol explica esse princípio, como

A divisão de uma organização em distintos departamentos, cada um independente dos outros, mas sujeitos a uma autoridade comum, possui diversas causas como o grande crescimento dos negócios, a diversidade das operações, exigindo diferentes competências ou a separação física das atividades (FAYOL, 2002, p. 9I3; 2003b, p. I83).

Esses ensinamentos de Fayol foram apresentados na AIG como os princípios da Divisão do Trabalho e da Autoridade e Responsabilidade, bem como na descrição do Corpo Social (estrutura organizacional). O texto do seu discurso de I908, entretanto, parece ser mais rico e oferece algumas oportunidades para melhor compreensão de seu pensamento. Fayol entende a estrutura organizacional como algo flexível, passível de mudanças, tendo em vista as necessidades advindas do tamanho, diversidade e expansão geográfica, um conceito essencialmente contingencial. 


\subsection{CENTRALIZAÇÃO}

Em seu discurso, Fayol explica o princípio da centralização como uma consequência natural do princípio da unidade de comando e diz que ela pode ser praticada de diferentes formas:

O campo pode ser deixado aberto para iniciativas individuais ou ele pode ser completamente sufocado. Podemos encontrar exemplos que vão desde uma estrutura rígida, com apenas obediência passiva, até um organismo vibrante, onde a liberdade de ação se espalha com a mais perfeita subordinação (FAYOL, 2002, p. 9I3; 2003b, p. I84).

Segundo Fayol (2002, p. 913; 2003b, p. I84) um líder pode conduzir todos os assuntos, tomar suas próprias decisões e impor uma obediência passiva. Entretanto "precisamos ter em conta o valor dos empregados. Somente a consideração das circunstâncias pode decidir o respectivo balanço entre poder e iniciativa, o que pode ser conveniente dar a todos os empregados". Defende ainda a "centralização compulsória, com a maior iniciativa individual possível” e complementa:

A força dos líderes é aumentada pela força que vem dos empregados do nível mais baixo e, desta forma, eles devem ser desenvolvidos na máxima extensão possível. Não nos esqueçamos, de passagem, que a satisfação pessoal e autoestima são frequentemente mais fortes que o interesse pessoal, quando ela vem para estimular a iniciativa individual (FAYOL, 2002, p. 9I3; 2003b, p. I84).

Com esses posicionamentos, Fayol demonstra a flexibilidade de seu pensamento. Nada é rígido e imutável. Tudo depende da avaliação das circunstâncias e cabe ao administrador a avaliação das diversas alternativas disponíveis. Nestes posicionamentos se percebe claramente as suas tendências que, mais tarde, alçadas pela Escola de Relações Humanas, vieram a redirecionar o pensamento administrativo a partir a década de I930.

\subsection{ORDEM}

Em seguida, Fayol define, em adição ao princípio da Unidade de Comando, o que denomina Unidade de Ação - que significa dirigir todos os esforços para o mesmo objetivo - e a Unidade de Propósito, que requer o mesmo pensamento, intenções e desejos entre todo o pessoal. Para o teórico: 
Unidade de Propósito requer os mesmos pensamentos, as mesmas intenções e os mesmos desejos entre todo o pessoal. [...] Se, além disso, a Unidade de Propósito existe entre todo o pessoal executivo, a organização oferece uma considerável garantia de sucesso. A Unidade de Propósito é talvez quase impossível de ser atingida em uma comissão. Não podemos esperar que cada proposta possa receber aprovação unânime, mas que isto não é necessário e pode até não ser desejável; oposição e contradição têm suas utilidades. Mas, quando a decisão é tomada, a ação começa e a discussão cessa (FAYOL, 2002, p. 9I4; 2003 b, p. I85-I86).

A diversidade de visões na organização deve ser explorada como suporte à construção do pensamento estratégico. Fayol reconhece essa poderosa ferramenta e demonstra, mais uma vez, a flexibilidade de seu pensamento e sua abertura ao contraditório.

\subsection{DISCIPLINA}

Fayol (2002, p. 9I4; 2003b, p. I86) recorre ao dicionário Larousse para definir disciplina como "conjunto de regras tácitas ou de regulamentos escritos destinados a assegurar boa ordem e regularidade em uma corporação, ou assembléia". Não se trata apenas de um princípio, mas de uma regra contingente ou dependente, para que sejam atingidos os objetivos da organização.

Em AIG, Fayol apresenta a "disciplina", um dos I4 Princípios da Administração, de uma forma mais coercitiva, focando a obediência e a assiduidade como sinais de respeito, impondo sanções como forma de evitar a repetição de indisciplinas. Entretanto, reconhece que, muitas vezes, problemas com disciplina podem ter origem na incapacidade dos chefes para lidar com conflitos com os subordinados, ou a existência de convênios (acordos trabalhistas) que não sejam suficientemente claros e equitativos (FAYOL, I994).

\subsection{PLANEJAMENTO}

Na palestra proferida em i6 de junho de I908, Fayol explicitou seu mais importante e abrangente princípio, o referente ao planejamento. Apresentado em AIG como um dos elementos da Administração, Prévoyance parece ser muito mais que um princípio. Traduzido por Wren, Bedeian e Breeze (2002) como Planning (literalmente "planejamento"), recebeu a tradução para o português, por Irene de Bojano e Mário de Souza, de “previsão” (FAYOL, I994). 
A dimensão do termo prévoir transcende uma rápida tradução. Parker e Ritson (2005a) citam que o termo utilizado possui duas dimensões: previdência e planejamento, sendo a primeira relacionada a prever o futuro, enquanto a segunda define o plano de ação a ser seguido.

Fayol advogava um enfoque de planejamento essencialmente contingencial, onde a avaliação do ambiente externo é fator que pode influir na modificação dos planos originais, de forma a adaptar-se a novas circunstâncias. A conjugação de incerteza ambiental e flexibilidade podem ser identificadas em seu texto: "O programa deve ser bastante flexível, suscetível de se adaptar às modificações julgadas necessárias, seja sob a pressão dos acontecimentos, seja por outra razão qualquer" (FAYOL, I994, p. 67).

De acordo com Parker e Ritson (2005a), Fayol reconhece que condições ambientais similares, encontradas por negócios similares, podem ser características que justificam comparar planos de negócios de distintas organizações. Nos dias de hoje seria algo próximo ao que denominamos benchmarking.

Planejar, um papel do departamento administrativo, é prever as necessidades de capital, mão de obra e canais de distribuição.

Prever e prover estas necessidades é o papel do departamento administrativo. Planejar é até mesmo mais necessário e muito mais difícil de realizar quando o empreendimento é grande, e quando os ciclos de produção e consumo são longos (FAYOL, 2002, p. 915; 2003b, p. I86).

Na palestra mencionada, Fayol (I994, p. 65) antecipa os conceitos que viria a defender em AIG, onde estabeleceu que "Prever, aqui, significa ao mesmo tempo calcular o futuro e prepará-lo; é, desde logo, agir [...]. A preparação do programa de ação é uma das operações mais importantes e mais difíceis de toda empresa". Ciente das dificuldades dessa tarefa, em seu discurso, Fayol não só as enfatiza, mas, também, destaca os riscos de um voo às cegas:

Tempo tem sido um fator essencial nas organizações, corremos o risco de ser desencorajados por dificuldades temporárias ou exultantes por sucessos momentâneos, se não temos um caminho ou programa para seguir (FAYOL, 2002, p. 915; 2003b, p. 186).

Neste ponto, algumas reflexões são importantes para compreender a amplitude dos conceitos desenvolvidos por Fayol. Primeiro, ele não possuía uma visão apenas centrada nos fatores de produção, capital e trabalho, mas tinha um olhar 
para o mercado, para a distribuição dos produtos. Wren (200I) lembra que Fayol foi um crítico da prática, comum em seu tempo, de deixar a área de vendas dirigir a produção. Isso porque, quando uma grande quantidade de carvão de alta qualidade era vendida, as minas tinham que escavar produtos de baixa e de alta qualidade, uma vez que esses diferentes produtos não podiam ser separados no processo de produção, gerando grandes estoques dos produtos que eram mais difíceis de comercializar. "Fayol buscou resolver este problema através do preparo de planos de produção e vendas, com registros de inventários, que o pessoal de vendas poderia utilizar para guiar suas atividades" (WREN, 200I, p. 477). Correlacionar atividades de produção e vendas, entretanto, não se constituía em atividade corriqueira dos administradores no início do século XX. Chandler (I990) destaca que, apenas a partir dos anos I920, os executivos das principais organizações norte-americanas passaram a utilizar essas técnicas.

Na visão de Fayol, o futuro deveria ser "calculado" e "preparado", ou seja, haveria de se pautar em uma postura mais próxima da gestão por previsão de mudanças, baseada nas variáveis decorrentes de ameaças e oportunidades previsíveis, que surgiu a partir da década de I950 (ANSOFF; McDONNELL, 2009), do que da gestão eminentemente baseada no controle, que seria natural esperar de um administrador do início do século XX. Ciente do impacto decorrente do tamanho da organização e de seu ciclo de produção, na tarefa de planejar, Fayol pregava um planejamento que visava "antecipar" e "enxergar" o futuro.

Fayol demonstra percepção da flexibilidade como elemento necessário no desenho de planos, na construção do futuro, antecipando a necessidade de se interagir com o ambiente, de se identificar as ameaças, de se lidar com as incertezas:

Longe de diminuir a liberdade de ação, o que é sempre bom ter, um programa amadurecidamente estudado irá fortalecer esta liberdade nos tempos difíceis, permitindo que toda atenção e forças disponíveis sejam focadas nas ameaças (FAYOL, 2002, p. 9I5; 2003b, p. I86).

Ao mesmo tempo que antecipa a identificação de ameaças como objeto de foco e atenção, Fayol demonstra sua preocupação com os efeitos contingentes do ambiente e exercita seu talento para metáforas biológicas 3 : 
Além disso, qualquer programa de longo prazo deve ser suscetível de ser alterado de acordo com variáveis, complexidade e instabilidade dos eventos. Como qualquer objeto vivo, o empreendimento industrial passa por contínuas transformações: o pessoal, o ferramental, os métodos, até mesmo os objetivos se modificam; o programa deve ser conduzido sem cessar, sempre que possível em harmonia com o ambiente (FAYOL, 2002, p. 915; 2003b, p. I86).

O teórico também alerta para os riscos dos desvios da rota traçada, de forma a garantir que todos os esforços possam convergir para os objetivos de longo prazo, para minimizar as incertezas e desenvolver um programa como resultado (FAYOL, 2002, 2003b).

Fayol enfatiza a necessidade de um orçamento anual para o próximo período financeiro, acrescido de um plano decenal que deve ser revisado sistematicamente. Para seu preparo devem ser revisadas as necessidades e as condições gerais do mercado, garantindo a continuidade das ideias e a estabilidade dos cenários. As dificuldades naturais para o preparo dessas projeções são contrapostas à afirmativa de que esse trabalho deve ser realizado apesar da resistência passiva muitas vezes encontrada, além da frustração proporcionada por planos que são alterados por eventos futuros não previstos (FAYOL, 2002, 2003b).

Ao incorporar a análise das condições de mercado (des conditions de marché, no original) e de cenários (la stabilité dans les desseins) no preparo de orçamentos, Fayol demonstra uma visão que foge ao que Ansoff e McDonnell (2009) classificam como "gestão por extrapolação", datada pelos autores como característica da década de I930 em diante, sendo mais próxima da "gestão por previsão [de mudanças]", baseada na análise de ameaças e oportunidades, origem do planejamento estratégico, que teria se desenvolvido somente a partir da década de I950.

Parker e Ritson (2005a) argumentam que Fayol tinha em mente uma visão de planejamento flexível, respondendo aos efeitos do ambiente, com enfoque contingencial, que admitia mudanças estratégicas significativas quando requerido pelas mudanças ambientais. Segundo os autores:

[...] a identificação e avaliação do significado das variáveis ambientais, o monitoramento dos planos e do desempenho dos concorrentes na indústria eram componentes vitais de seu enfoque contingencial de planejamento. Isto era também estratégico, no sentido em que ele advogava um planejamento com horizonte de longo prazo para múltiplos períodos (PARKER e RITSON, 2005a, p. I86). 
Wren (I972), citado por Parker e Ritson (2005a, p. I80), menciona que "a ênfase de Fayol no planejamento de longo prazo foi uma contribuição única para o pensamento gerencial".

\subsection{ORGANOGRAMA}

A estrutura organizacional é apresentada por Fayol através da descrição do organograma da companhia Comambault. O organograma apresentado por Fayol, em sua mencionada palestra de I908, possui as funções de: (a) pessoal (recrutamento, organização e operação); (b) exploração e manufatura; (c) manutenção e construção; (d) vendas e compras; (e) contabilidade, finanças e diversos. Ou seja, é composto de um grupo de diversos departamentos secundários, os quais não são necessariamente parte dos departamentos principais (FAYOL, 2002, 2003b).

Assim, a estrutura organizacional preconizada por Fayol era, além de flexível, direcionada para a descentralização das atividades, concedendo a máxima autonomia aos empregados. Além disso, Fayol preocupava-se em desenhar uma estrutura que pudesse ser ágil no atendimento aos clientes, ou seja, demonstrava uma visão claramente focada no mercado, no mundo exterior, para fora da organização. Na parte III de AIG, Fayol (2003a) explica a estrutura da área comercial da Comambault, demonstrando a aplicação dos princípios que preconizava relativos à centralização, divisão de responsabilidades, unidade de comando e a obrigação de andar rápido, de dar satisfação aos clientes.

Dessa forma, Fayol advogava não somente a definição clara do organograma e dos respectivos canais de autoridade e comunicação, mas, também, o desenvolvimento do que denomina "plano de serviços", definindo "limites topográficos" de cada departamento sob o ponto de vista da organização e do controle de ordem material (FAYOL, 2002, 2003b).

O pensamento de Fayol sobre estrutura, expresso em seu discurso de I908, apresenta-se, portanto, flexível, aberto para as mudanças originadas das demandas do ambiente. Ele demonstra entender e segregar os diferentes papéis daqueles que estão "no campo", atendendo diretamente os clientes, daqueles que estão "no escritório central", desempenhando as tarefas que Chandler (I990, p. 8) denomina de "administração", quais sejam "ações e ordens executivas, bem como as decisões tomadas para coordenar, avaliar e planejar o trabalho da organização e a alocação de seus recursos".

\subsection{REUNIÕES E RELATÓRIOS}

Defensor da comunicação e do eficaz gerenciamento de equipes, Fayol, ao propor a dinâmica operacional de uma organização, complementa: 
Líderes habilidosos encontram a oportunidade para entender seus subordinados, para estimular suas iniciativas e para trazer entre eles a unidade de ação e, com grande possibilidade, a unidade de propósito (FAYOL, 2002, p. 9I6; 2003b, p. I88).

Alegava também que a "unidade de propósito e de ação" seriam facilitadas por reuniões periódicas bem como por relatórios escritos (FAYOL, 2002, 2003b).

\subsection{CONTABILIDADE}

Fayol compara a contabilidade a um termômetro, que mede as condições e a saúde da organização (um ser vivo, portanto). Defensor da necessidade de transparência e da motivação dos quadros, Fayol prega a divulgação interna das informações produzidas pela contabilidade a todos os empregados. Também, foca seus comentários na necessidade de acuracidade e rapidez, além de associar a utilização da informação como guia para decidir eventuais mudanças de rumo (FAYOL, 2002, 2003b).

\section{CONCLUSÃO}

Apesar de ser considerado um dos teóricos mais importantes do pensamento administrativo, Fayol é surpreendentemente pouco estudado e, até mesmo, pouco conhecido em sua dimensão humana e científica. A reconstrução do perfil do mestre, cuja imagem, embaçada por estereótipos do funcionalismo, é frequentemente apresentada aos estudantes de Administração de forma equivocada, pois empobrecida no seu real valor, faz-se necessária, até mesmo para que seja possível compreender, de forma mais abrangente e profunda, a própria história da evolução do conhecimento na Ciência da Administração.

Esse estágio superior de evolução de conhecimento é alcançado com o desenvolvimento de posturas antecipatórias de gestão, que viriam a se contrapor ao posicionamento estático e meramente reativo que, até então, caracterizava a condução dos negócios e a administração das organizações. Esse novo posicionamento agregaria não somente os conhecimentos acumulados para a avaliação dos impactos do ambiente na organização, mas também aqueles necessários para influir no contexto do próprio ambiente. A construção de ações e de ferramentais de gestão necessárias para lidar com um ambiente cada vez mais hostil e imponderável foi também o suporte para desenvolvimento dos conhecimentos relacionados às estratégias organizacionais. 
Esta avaliação é possível não somente através de uma atenta releitura de AIG, mas também pela análise dos conceitos que seu autor desenvolveu e que só muito recentemente vieram a público, e que demonstram que Fayol lançou as bases conceituais da Escola de Relações Humanas e da Teoria Contingencial. Este estudo identificou três gerações de fayolistas, estudiosos que se dedicaram a divulgar e analisar seus ensinamentos. A primeira compreende seus discípulos e seguidores diretos, produzindo seus trabalhos entre I900 e I920; a segunda geração atuou subsequentemente, divulgando as ideias do fayolismo até a década de I950; e a terceira, somente a partir dos anos I980, quando surge uma nova leva de pesquisadores, denominados neste trabalho de "os novos fayolistas", que viriam a trabalhar a partir da descoberta de novos textos de Fayol. De fato, escritos praticamente desconhecidos de Fayol - como a palestra feita em I9०8, divulgada em 2002, e a Parte III de AIG, divulgada em 2003 - expõem um pensador muito mais profundo e surpreendentemente avançado em relação à sua época, revelando que o teórico trabalhava e produzia sua doutrina dentro de uma perspectiva que considerava as variáveis ambientais, a força construtiva das relações humanas, a necessidade da educação como fator de diferenciação e a adoção de uma postura administrativa eminentemente estratégica.

Os conceitos desenvolvidos por Fayol, como executivo e como teórico, e que emergem dos textos estudados, demonstram o nascedouro, no início do século XX, de práticas comuns na administração das organizações do século XXI, como a estrutura descentralizada, programas de educação continuada e de sucessão, a adoção de procedimentos denominados benchmarking, o planejamento estruturado e com foco no longo prazo, a governança corporativa e a administração estratégica.

Conclui-se, pois, que apesar de Fayol já destacar, em I908, alguns princípios de seu pensamento que demonstram sua forte percepção estratégica, os estudiosos da Administração somente reconhecem que esses conceitos teriam surgido a partir da década de i960. A evolução dos sistemas de administração e de planejamento empresarial evoluíram da denominada Gestão por Controle, implementada no início do século XX e vigorando até os anos I930, quando foi substituída pela Gestão por Extrapolação, essa voltada a desenhar o futuro a partir dos acontecimentos do passado, e que foi suplantada a partir dos anos I950 pela Gestão por Previsão, uma semente do que viria a ser o Planejamento Estratégico. O que fica demonstrado é que Fayol empregava e dominava, já nos primeiros anos do século XX, conceitos de planejamento que a literatura em Administração situa historicamente muitos anos depois. 


\section{POSTHUMOUS PUBLICATIONS OF HENRI FAYOL: A NEW LOOK AT HIS ADMINISTRATIVE THEORY}

\section{ABSTRACT}

The French engineer Henri Fayol (I84I-I925) is usually introduced to the students of Management as the Father of Classical School, which however, would be a misrepresentation of the breadth of his contribution to management. In addition, he is often associated with his contemporary, the American theorist Frederick Taylor, both credited with having advocated an authoritarian model of management. Recent researchers, however, have found, through examining unpublished and rare documents, an unknown portrait of this pioneer. This paper comes out from extensive available bibliographic sources, published and unpublished, which include studies developed by researchers from France, United States, Canada, Australia and Japan. These researchers make up a small group of scholars, here called "new fayolists" because, after years of almost amnesia in academia, they resumed interest in the contributions of Henri Fayol. These studies uncover concepts, developed by Fayol, which anticipated aspects of coming management theories like human relations movement, systems-based contingency theory and strategic planning. By presenting this recent research about the man and theorist Henri Fayol, this study allows, to the Portuguese language students and scholars, access to writings and speeches of Henri Fayol that remain untranslated and unpublished until now.

\section{KEYWORDS}

Henri Fayol; Management; Organizational strategies; Organizational theory; Planning.

\section{PUBLICACIONES POSTUMAS DE HENRI FAYOL: REVISANDO SU TEORIA ADMINISTRATIVA}

\section{RESUMEN}

El ingeniero francés Henri Fayol (I84I-I925) se suele presentar a los estudiantes de Ingeniería Comercial como el Padre de la escuela clásica de Administración, que resulta ser una representación limitada de la magnitud de su contribución a la evolución del pensamiento Administración. Por otra parte, se asocia a menudo 
con su contemporáneo, el teórico estadounidense Frederick Taylor, puesto que ambos son designados como defensores del modelo autoritario de gestión. Sin embargo, recientemente, los investigadores han descubierto a través de examen de documentos raros e inéditos, un retrato desconocido de ese pionero. Este estudio es resultado de una investigación que buscaba descubrir las fuentes de información bibliográfica disponibles, publicadas o no, incluyendo los resultados de estudios realizados por investigadores de Francia, EE.UU., Canadá, Australia y Japón. Estos investigadores forman un pequeño grupo de estudiosos, aquí llamado "nuevos fayolistas" porque vuelven, después de años de casi amnesia en el mundo académico, el interés por las aportaciones de Henri Fayol. Los estudios revelaron conceptos desarrollados por Fayol que anticipan aspectos de las teorías y prácticas de la administración que, sólo más tarde se desarrollaría como la Escuela de Relaciones Humanas, Teoría de la Contingencia y Planificación Estratégica. Al presentar las últimas investigaciones sobre el hombre y el teórico Henri Fayol, este estudio permite a los profesores y estudiantes de lengua Portuguesa, el acceso a los escritos y conferencias de su autoría, que hasta entonces habían permanecido desconocidos.

\section{PALABRAS CLAVE}

Henri Fayol; Administración; Estrategias organizacionales; Teoría organizacional; Planificación.

\section{REFERÊNCIAS}

ANSOFF, H. I.; McDONNELL, E. J. Implantando a administração estratégica. São Paulo: Atlas, 2009 .

BEDEIAN, A. G. The administrative writings of Henri Fayol: a bibliographic investigation. Monticello: Vance Bibliographies, I979.

I998.

Exploring the past. Journal of Management History, Bingley, v. 4, n. I, p. 4-I5, Oct./Dec.

BLANCPAIN, F. Les cahiers inédits d'Henri Fayol. Bulletin International d'Administration Publique, v. 28 e 29, p. I-48, I974.

BREEZE, J. D. Henri Fayol's résume de la doctrine administrative: translation, commentary and analysis of its historical development. I980. Dissertação (Mestrado em Administração)-St. Mary's University, Halifax, I980.

Henri Fayol's basic tools of administration. Proceedings of the 41 st. Meeting of the Academy of Management, Montréal, p. I0I-I05, Aug. I98I.

Harvest from the archives: the search for Fayol and Carlioz. Journal of Management, v. II, n. I, p. 43-54, I985. 
BREEZE, J. D. Henri Fayol's Centre for Administrative Studies. Journal of Management History, Bingley, v. I, n. 3, p. 37-62, Jul./Sept. I995.

BRODIE, M. Fayol on administration. London: Grant and Green, I967. p. 3.

CARLIOZ, J. Étude sur les associations industrielles et commerciales. Paris: Librarie Centrale des Chemins de Fer, I9O0.

CHANDLER JUNIOR, A. D. Strategy and structure: chapters in the history of the American industrial enterprise. Cambridge: MIT Press, I990. 463 p.

CUTHBERT, N. Fayol and the principles of organization. In: TILLETT, A.; KEMPNER, T.; WILLS, G. (Ed.). Management thinkers. London: Penguin, I970.

DALE, E. The great organizers. New York: McGraw-Hill, I960.

FAYOL, H. Administração industrial e geral. São Paulo: Atlas, I994. I38 p.

. L'exposé des principles généraux d'administration. In: WREN, D. A.; BEDEIAN, A. G.;

BREEZE, J. D. The foundations of Henri Fayol's administrative theory. Management Decision, Bingley, v. 40, n. 9, 2002.

Administration industrielle et générale. 3e. partie: observations et expériences personnelles.

In: PEAUCELLE, J. L. (Org.). Henri Fayol inventeur des outils de gestion. Paris: Economica, 2003a.

. L'exposé des principles généraux d'administration. In: PEAUCELLE, J. L. (Org.). Henri Fayol inventeur des outils de gestion. Paris: Economica, 2003b. p. 906-918.

MORGAN, G. Imagens da organização. São Paulo: Atlas, 2007.

PARKER, L. D.; RITSON, P. A. Revisiting Fayol: anticipating contemporary management. British Journal of Management, Hoboken, v. I6, p. 175-194, Sept. 2005 a.

. Fads, stereotypes and management gurus: Fayol and Follet today. Management Decision, Bingley, v. 43, n. Io, p. 1335-1357, $2005^{\mathrm{b}}$.

PEAUCELLE, J. L. (Org.). Henri Fayol inventeur des outils de gestion. Paris: Economica, 2003a.

Présentation et commentaire du livre de Henri Fayol administration industrielle et générale. In: . (Org.). Henri Fayol inventeur des outils de gestion. Paris: Economica, 2003b. p. I49-192.

L'outillage administratif de Fayol. In : (Org.). Henri Fayol inventeur des outils de gestion. Paris: Economica, 2003c. p. 207-235.

Henri Fayol et la recherche-action. In: (Org.). Henri Fayol inventeur des outils de gestion. Paris: Economica, 2003d. p. 29I-308.

REID, D. The genesis of fayolism. Genêse du Fayolism, v. 28, p. 75-93, I986.

Fayol: excès d'honneur ou excès d'indignité? Revue Française de Gestion, p. I5I-I59, I988.

Reading Fayol with 3D glasses. Journal of Management History, Bingley, v. I, n. 3, p. 63-7I, Jul./Sept. I995.

SASAKI, T. Le pionnier du management contemporain: Henri Fayol, sa vie, son management stratégique et sa théorie du management. Mimeo, I987. p. 20-30.

Henri Fayol's family relationships. Journal of Management History, Bingley, v. I, n. 3, p. 13-20, Jul./Sept. I995.

URWICK, L. F. The function of administration with special reference to the work of Henri Fayol. In: GULICK, L.; URWICK, L. F. (Ed.). Papers on the science of administration. New York: Institute of Public Administration, I937. 
VANUXEM, P.; WILBOIS, J. Essai sur la conduite des affaires et la direction des hommes. Paris: Payot, I9I9.

VERNEY, H. Le fondateur de la doctrine administrative: Henry Fayol. Paris: Dunod, I925.

WREN, D. A. The evolution of management thought. New York: The Ronald Press, I972.

Henri Fayol: learning from experience. Journal of Management History, Bingley, v. I, n. 3, p. 5-I2, Jul./Sept. I995.

WREN, D. A. Henri Fayol as strategist: a nineteenth century corporate turnaround. Management Decision, Bingley, v. 39, n. 6, p. 475-487, 200I.

WREN, D. A.; BEDEIAN, A. G.; BREEZE, J. D. The foundations of Henri Fayol's administrative theory. Management Decision, Bingley, v. 40, n. 9, p. 906-918, 2002. 